\title{
PERANCANGAN SISTEM INFORMASI PENGGAJIAN KARYAWAN PADA PT DUTA VISUAL NUSANTARA TV7 TRANS7
}

\author{
Radea Arta Kusuma1, Muhamad Haikal², Purwanti $^{3}$ \\ ${ }^{1,2,3}$ Universitas Indraprasta PGRI \\ Jl. Raya Tengah No. 80, Kel. Gedong, Kec. Pasar Rebo. Jakarta Timur \\ 1radea_ak@yahoo.com, ${ }^{2}$ Muhamadhaikal220220@gmail.com, ${ }^{3}$ pwanty7@gmail.com
}

\begin{abstract}
ABSTRAK
Sejalan dengan perkembangan ilmu dan teknologi PT Duta Visual Nusantara Tivih Tujuh Trans7 akan membangun sistem informasi penggajian sebagai upaya untuk dapat terus berjalan dan bertahan dalam persaingan yang semakin kompetitif. Penelitian ini bertujuan untuk mengetahui aplikasi ms exel yang sedang berjalan, membuat aplikasi penggajian karyawan, melakukan analisis dan pengujian aplikasi serta untuk melakukan implementasi penggajian karyawan. Rancangan yang dihasilkan berupa rancangan sistem yang digambarkan menggunakan Diagram Alir Data. Perancangan sistem informasi penggajian karyawan berbasis desktop dapat mempermudah untuk proses pengolahan data yang efisien dan akurat demi mencegah adanya keterlambatan dan ketidakcocokan data.
\end{abstract}

Kata Kunci: Perancangan, Aplikasi, Penggajian

\begin{abstract}
In line with the advance of science and technology PT Duta Visual Nusantara Tivih Tujuh Trans7 will establish remuneration system information as an attempt to keep running and survive in aggresive competition nowadays. This research aims to find out the current ms exel applications, make employee payroll applications, conduct analysis and application testing and to implement employee payroll. The design resulted is system design described using Diagram Alir Data. Planning information systems based desktop payroll information can make for efficient data processing and accurate in order to prevent the existence of delays and a mismatch of data.
\end{abstract}

Key Word: Planning, Application, payment payroll.

\section{PENDAHULUAN}

Perkembangan teknologi terutama di bidang komputer saat ini berkembang sangat cepat di setiap bidang kerja. Perkembangan teknologi tersebut menuntut para perusahaan untuk lebih maju dalam melakukan pengelolaan data dengan baik. Dengan memanfaatkan teknologi sistem informasi diharapkan dapat membantu dalam pekerjaan pemprosesan, pengolahan data-data penting serta pelayanan sebagaimana diharapkan oleh perusahaan.

Sistem infomasi penggajian merupakan salah satu teknologi yang paling dibutuhkan oleh perusahaan untuk melakukan pengolahan data gaji karyawannya. Data-data yang diperlukan dalam sebuah proses penggajian dikelola dan diolah secara otomatis oleh sistem, agar kemudian dapat menjadi sebuah informasi yang dibutuhkan oleh perusahaan. Sistem informasi diciptakan agar berbagai macam proses manual dapat dikerjakan secara komputerisasi sehingga lebih efektif dan efisien.
Pengolahan gaji pada PT Duta Visual Nusantara Tivi Tujuh (TRANS7) masih menggunakan program bantuan microsoft excel. Sehingga timbul permasalahan yang terjadi pada sistem penggajian antara lain : penyimpanan data yang kurang baik karena belum menggunakan basis data, data gaji karyawan harus diperiksa berulang kali pada kolom-kolom yang diisi dalam program bantu Ms. Excel yang digunakan, terjadinya kesalahan perhitungan gaji karyawan, dan proses pembuatan laporan dan slip gaji karyawan yang membutuhkan waktu relatif lama karena harus di rekap satu per satu karyawan setiap bulannya. Untuk mengimbangi kemajuan teknologi, maka perlu adanya sistem informasi pengolahan gaji karyawan yang dapat meningkatkan kualitas kerja karyawan yang efisien. Di sini akan dirancang dan dibuat sebuah sistem informasi pengolahan gaji karyawan, perancangan tersebut dimaksudkan untuk memudahkan karyawan PT Duta Visual 
Nusantara Tivi Tujuh Trans7 dalam melaksanakan pengolahan gaji karyawan.

Dari uraian latar belakang yang telah diuraikan maka dapat dibuat rumusan masalah yang nantinya akan dibahas, yaitu Bagaimana membuat sistem penggajian karyawan yang terkomputerisasi sehingga nantinya dapat meminimalisir kesalahan?. Penelitian akan dibatasi pada bahasan mengenai sistem penggajian karyawan. Objek penelitian di PT Duta Visual Nusantara Tivi Tujuh Trans7, Sistem ini dibangun menggunakan bahasa pemrograman java netbeans 8.0.2, MySQL sebagai databasenya, Sistem ini dirancang berbasis desktop.

Dari uraian latar belakang yang telah diuraikan maka dapat dibuat rumusan masalah yang nantinya akan dibahas, yaitu Bagaimana membuat sistem penggajian karyawan yang terkomputerisasi sehingga nantinya dapat meminimalisir kesalahan?. Penelitian akan dibatasi pada bahasan mengenai sistem penggajian karyawan. Objek penelitian di PT Duta Visual Nusantara Tivi Tujuh Trans7, Sistem ini dibangun menggunakan bahasa pemrograman java netbeans 8.0.2, MySQL sebagai databasenya, Sistem ini dirancang berbasis desktop.

Tujuan Penelitian adalah Menghasilkan perancangan aplikasi untuk sistem informasi penggajian karyawan PT Duta Visual Nusantara Tivi Tujuh Trans7. Manfaat dari hasil penelitian ini yaitu Memberi gambaran sistem kepada pihak administrasi PT Duta Visual Nusantara Tivi Tujuh Trans7dalam pengolahan data penggajian karyawan.

Pengertian Perancangan menurut Susanto dalam Akhmad Syukron dan Noor Hasan (2015:29) menyatakan "Perancangan adalah spesifikasi umum dan terinci dari pemecahan masalah berbasis komputer yang telah dipilih selama tahap analisis". Sedangkan Sistem Informasi menurut Hutahaean (2015:13), mengungkapkan bahwa : "Sistem informasi adalah suatu sistem di dalam suatu organisasi yang mempertemukan kebutuhan pengelolaan transaksi harian, mendukung operasi, bersifat manajerial, dan kegiatan strategi dari suatu organisasi dan menyediakan pihak luar tertentu dengan laporan - laporan yang dibutuhkan".

Pengertian Sistem Informasi Penggajian menurut Zaki Baridwan dalam Brestina Gultom (2014:96), mengungkapkan yang bahwa "Sistem informasi penggajian adalah suatu kerangka dari prosedur paling berhubungan sesuai dengan skema yang menyeluruh untuk melaksanakan kegiatan dan fungsi utama perusahaan yang berhubungan dengan penggajian".

Sedangkan pengertian Gaji,“Gaji umumnya merupakan pembayaran atas penyerahan jasa yang dilakukan oleh karyawan yang mempunyai jenjang jabatan manajer, sedangkan upah umumnya merupakan pembayaran atas penyeraha jasa yang dilakukan oleh karyawan pelaksana (buruh)" (2016:309 Mulyadi)

Pengertian Diagram Alir Data (DAD) menurut Sukamto dan Shalahudin (2015:70), Data Flow Diagram (DFD) atau dalam bahasa Indonesia menjadi Diagram Alir Data (DAD) adalah reprensentasi grafik yang menggambarkan aliran informasi dan transformasi informasi yang diaplikasikan sebagai data yang mengalir dari masukan (input) dan keluaran (Output).

Pengertian Entity Relationship Diagram (ERD) menurut Sutanta (2011:91) "ERD merupakan suatu model data yang dikembangkan berdasarkan objek. ERD digunakan untuk menjelaskan hubungan antara data dalam bsis data. Sehingga jika penyimpanan basis data kepada pengguna secara logis".

Pengertian Database menurut Rosa dan Shalahuddin (2016:43) "sistem data base adalah sistem terkomputerisasi yang tujuan utamanya adalah memelihara data yang sudah diolah atau informasi dan membuat informasi tersedia saat dibutuhkan".

Pengertian Java menurut Rusli (2016:2) "Java adalah bahasa pemrograman yang tergolong pada high level language (mudah bagi manusia untuk memahami). Mengingat kata$\mathrm{kata} /$ statemennya menyerupai bahasa manusia (english). Namun demikian, dalam 
penulisannya memerlukan aturan (syntax) yang ketat".

Pengertian Mysql menurut Sibero (2013:97) "Mysql atau dibaca My Sekuel adalah suatu RDBMS (Relational Database Management System) yaitu aplikasi sistem yang menjalankan fungsi pengolahan data"

\section{METODE PENELITIAN}

Menurut Sugiyono (2018:2) metode penelitian pada dasarnya merupakan cara ilmiah untuk mendapatkan data dengan tujuan dan kegunaan tertentu. Cara ilmiah berarti kegiatan penelitian yang didasarkan pada ciriciri keilmuan, yaitu rasional, empiris, dan sistematis.

Metode yang cocok digunakan dalam penelitian ini meliputi dua metode yaitu:

Metode kualitatif Teori Dasar (Grounded Theory), yaitu Metode teori dasar merupakan penelitian yang dilakukan untuk menemukan suatu teori atau menguatkan teori yang sudah ada dengan mengkaji prinsip dan kaidah dasar yang ada lalu dibuat kesimpulan. Pengumpulan data metode teori dasar ini dilakukan dengan:

Observasi yaitu metode dengan cara mengamati kegiatan yang dilakukan selama penulis melakukan kegiatan di lapangan.

Studi literature yaitu metode dengan mencari sumber dari data perusahaan, buku penunjang dan internet.

Wawancara yaitu mencari informasi dengancara melakukan wawancara kepada pihak perusahaan.

Dokumentasi yaitu dengan cara melihat dan mencatat data yang ada pada dokumen atau arsip pada PT Duta Visual Nusantara Tivi Tujuh (TRANS7).

Metode pengembangan perangkat lunak Waterfall yaitu model yang dikembangkan untuk pengembangan perangkat lunak, membuat perangkat lunak. model berkembang secara sistematis dari satu tahap ke tahap lain dalam mode seperti air terjun. Model ini mengusulkan sebuah pendekatan kepada pengembangan software yang sistematik dan sekuensial yang mulai dari tingkat kemajuan sistem pada seluruh analisis, desain, kode, pengujian dan pemeliharaan.

\section{HASIL DAN PEMBAHASAN}

Hasil dari penelitian yang dilakukan mendapatkan kesimpulan permasalahan yang dihadapi pada sistem pengolahan penggajian karyawan PT Duta Visual Nusantara Tivi Tujuh (TRANS7) yang sedang berjalan saat ini adalah sebagai berikut :

1. Sistem penggajian karyawan yang berjalan saat ini masih berjalan secara semi komputerisasi proses perhitungannya pun menggunakan Microsoft excel.

2. Proses sistem penggajian karyawan yang berjalan masih belum optimal dikarenakan ketika penginputan data sering ditemukan data ganda dan kesalahan dalam penginputan sehingga mengakibatkan kesalahan dalam perhitungan dan pembayaran gaji karyawan.

3. Proses perhitungan gaji memerlukan waktu yang lebih banyak dikarenakan memerlukan ketelitian tinggi, resiko data hilang pun bisa terjadi, sehingga membutuhkan waktu yang lama dalam pencarian data.

Berdasarkan analisis yang telah dilakukan oleh penulis, maka dapat disimpulkan alternatif pemecahan masalah sebagai berikut:

1. Perlu merancang sistem yang lebih terotomatis dibandingkan sistem sebelumnya.

2. Membuat sistem yang sudah berbasis java dekstop, agar sistem yang di usulkan dapat mempermudah bagian keuangan.

3. Perlu dibuatkan sistem yang memiliki penyimpanan data yang lebih aman supaya data tidak hilang dan dapat mempermudah dalam pencarian data lebih cepat. 


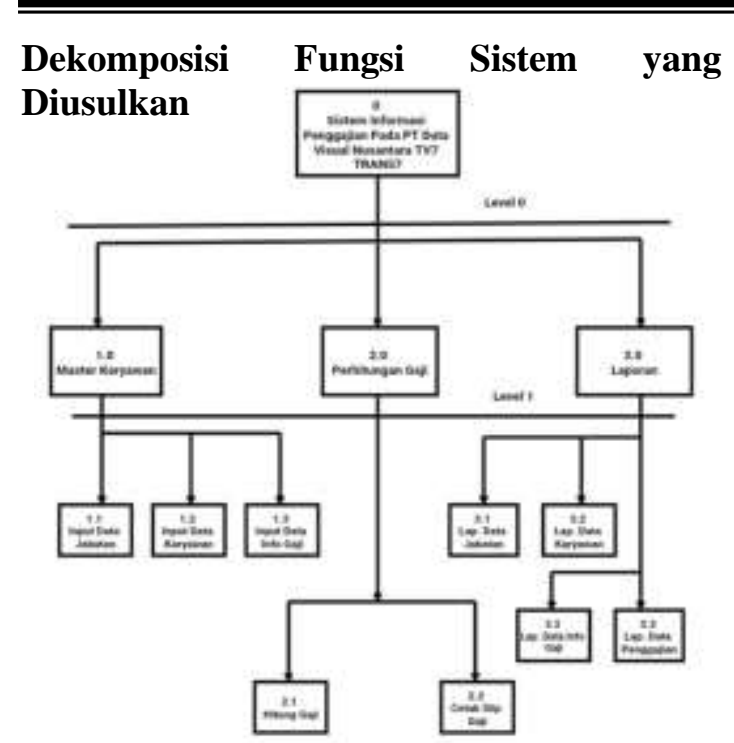

Gambar 1. Dekomposisi Fungsi Sistem yang Diusulkan

Diagram konteks yang diusulkan

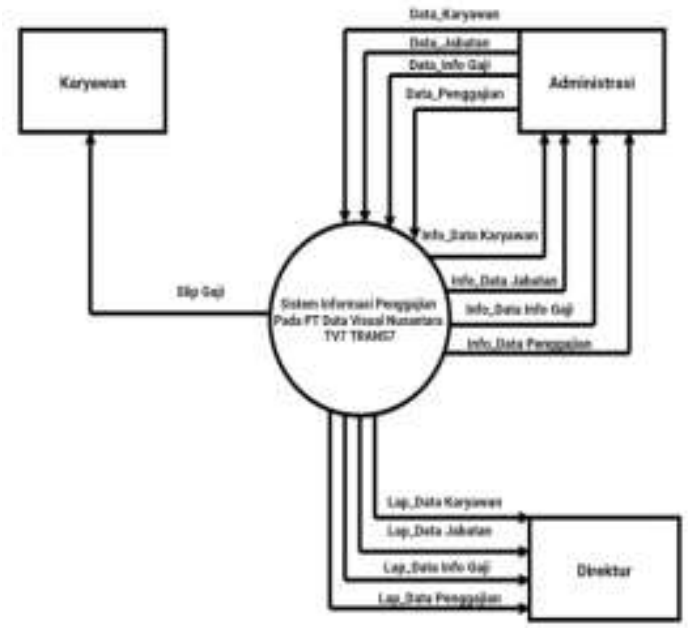

Gambar 2. Diagram Konteks yang Diusulkan

\section{Tampilan Layar Login}

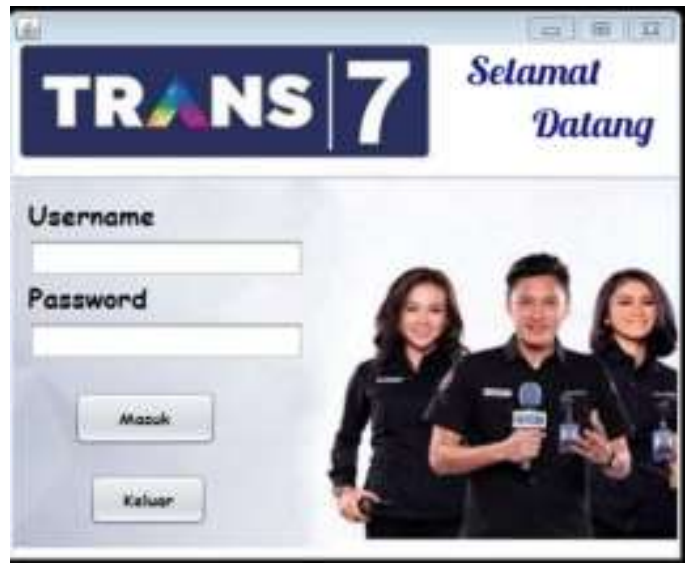

Gambar 3. Tampilan Login

Tampilan ini menampilkan username dan password. Maka menu utama akan tampil.
Tampilan Layar Menu Utama

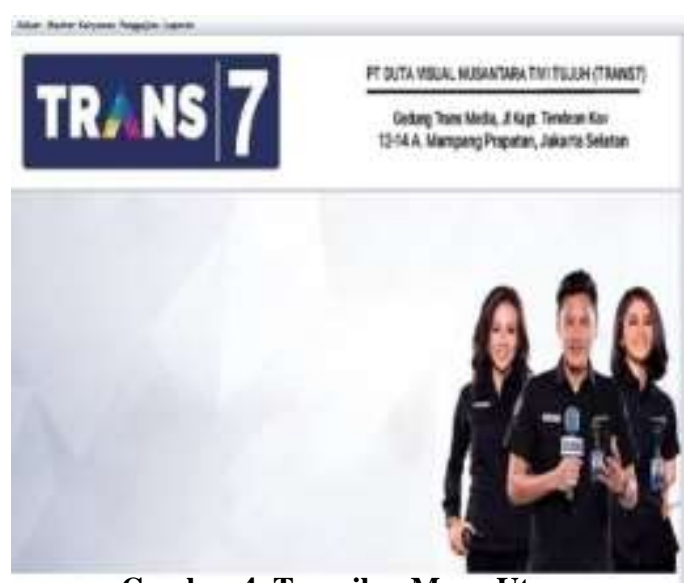

Gambar 4. Tampilan Menu Utama

Menu utama merupakan tampilan awal program yang terdiri dari beberapa menu.

\section{Tampilan Form Data Jabatan}

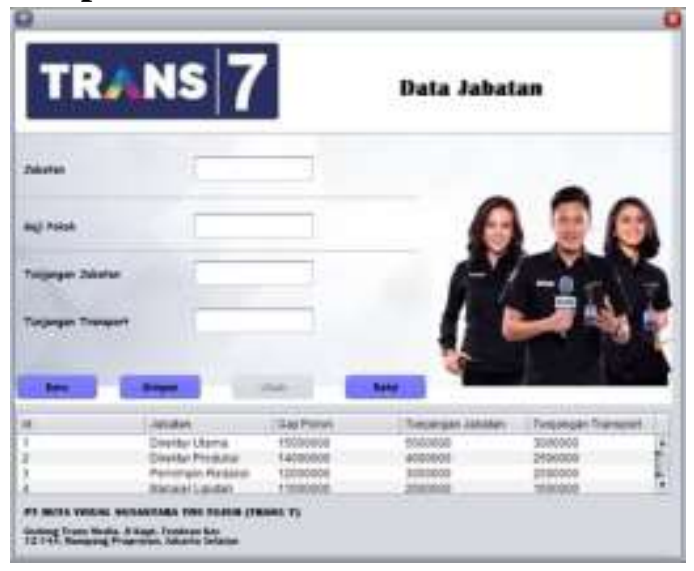

Gambar 5. Tampilan Form Data Jabatan

Form data jabatan digunakan untuk menginput data jabatan.

\section{Tampilan Form Data Karyawan}

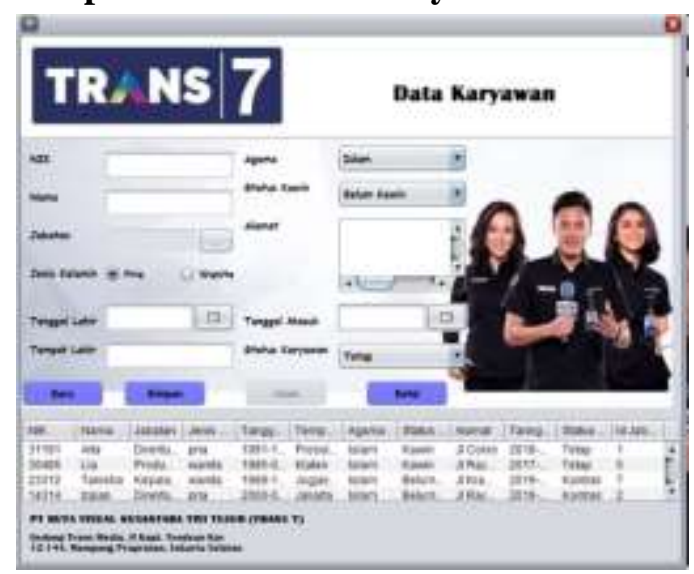

Gambar 6. Tampilan Form Data Karyawan

Form data karyawan digunakan untuk menginput data karyawan. 


\section{Tampilan Form Data Info Gaji}

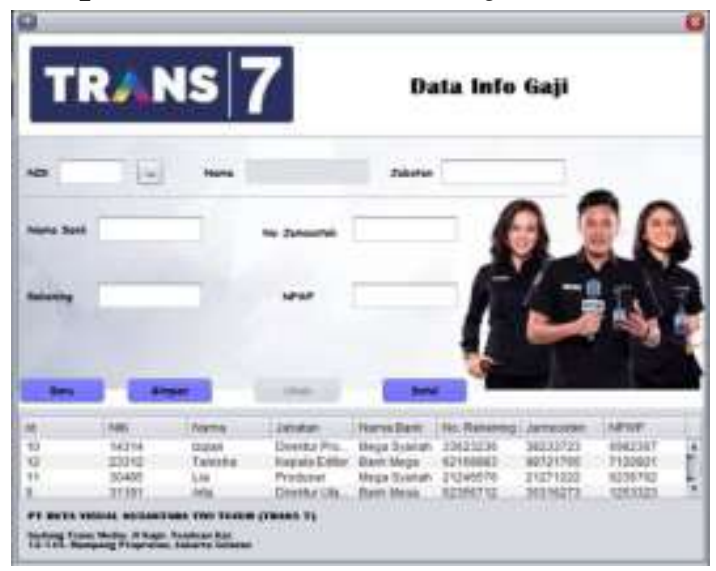

Gambar 7. Tampilan Form Data Info Gaji

Form data info gaji digunakan untuk menginput data info gaji.

\section{Tampilan Format Data Penggajian}

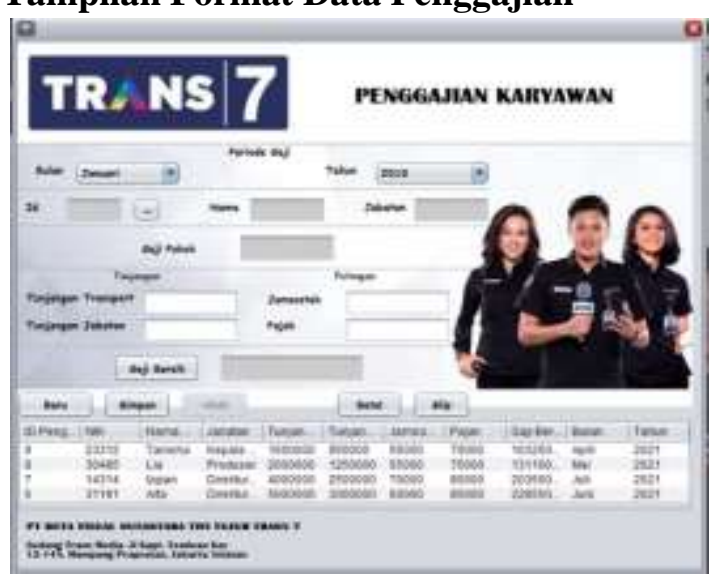

Gambar 8. Tampilan Form Data Penggajian

Form ini menampilkan proses kegiatan pengolahan gaji karyawan dan cetak slip gaji.

\section{Tampilan Laporan Data Jabatan}

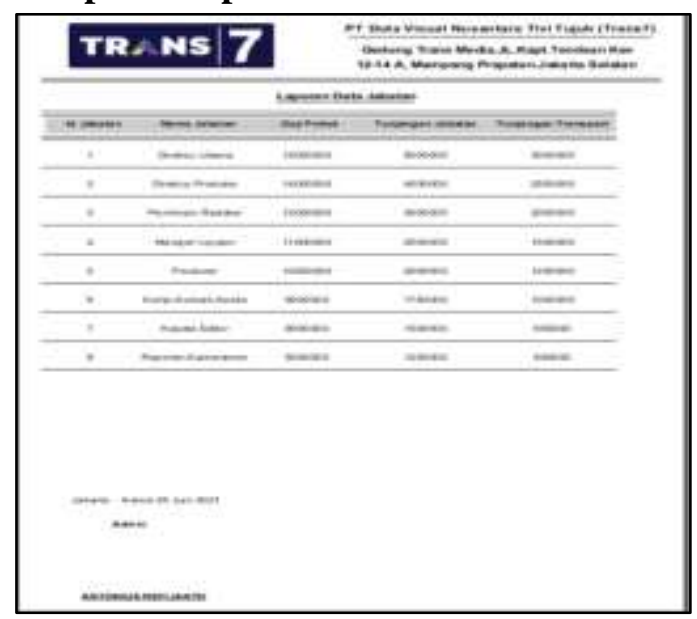

Gambar 9. Tampilan Laporan Data Jabatan

Merupakan laporan dari data jabatan.
Tampilan Laporan Data Karyawan

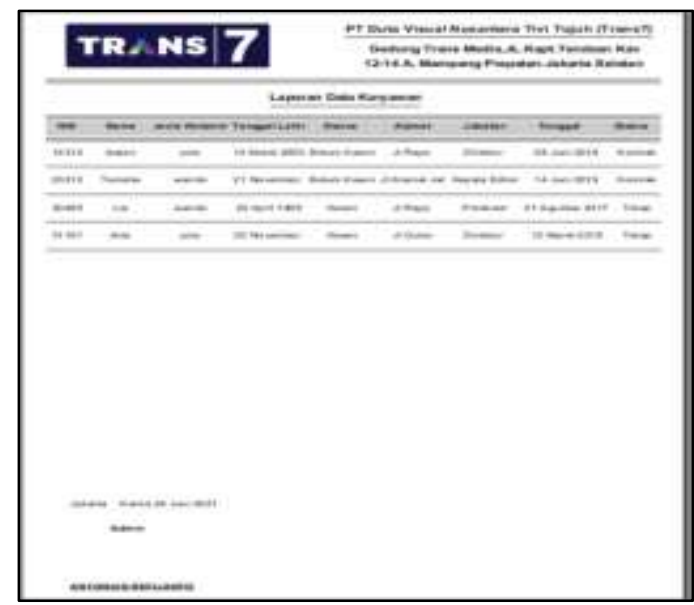

Gambar 10. Tampilan Laporan Data Karyawan

Merupakan laporan dari data karyawan.

\section{Tampilan Laporan Data Info Gaji}

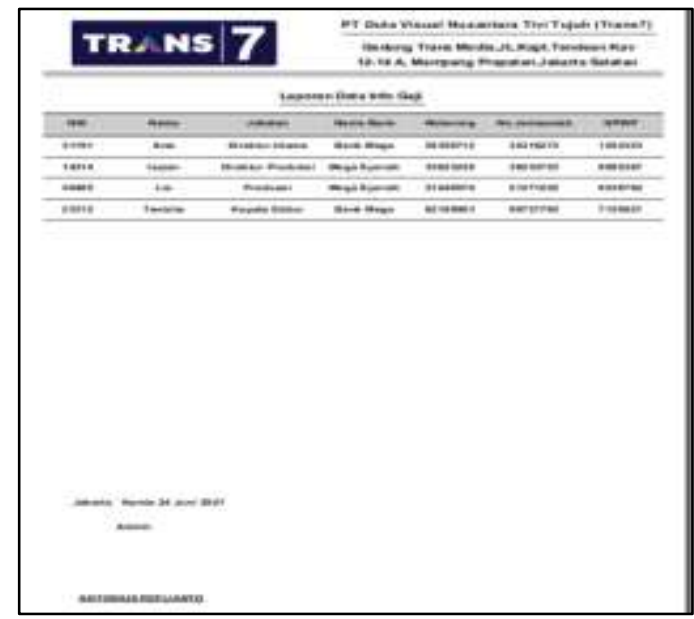

Gambar 11. Tampilan Laporan Data Info Gaji

Merupakan laporan dari data info gaji.

Tampilan Laporan Data Penggajian

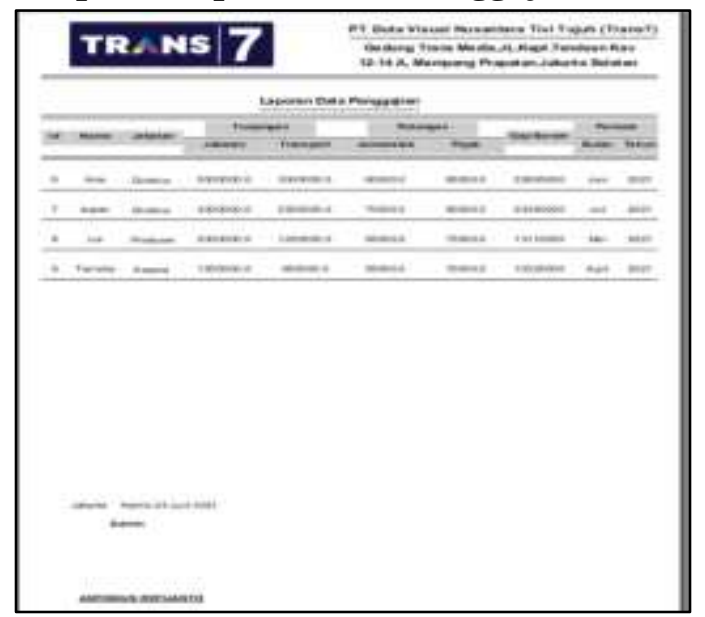

Gambar 12. Tampilan Laporan Data Penggajian

Merupakan laporan dari data penggajian. 


\section{Tampilan Slip Gaji}

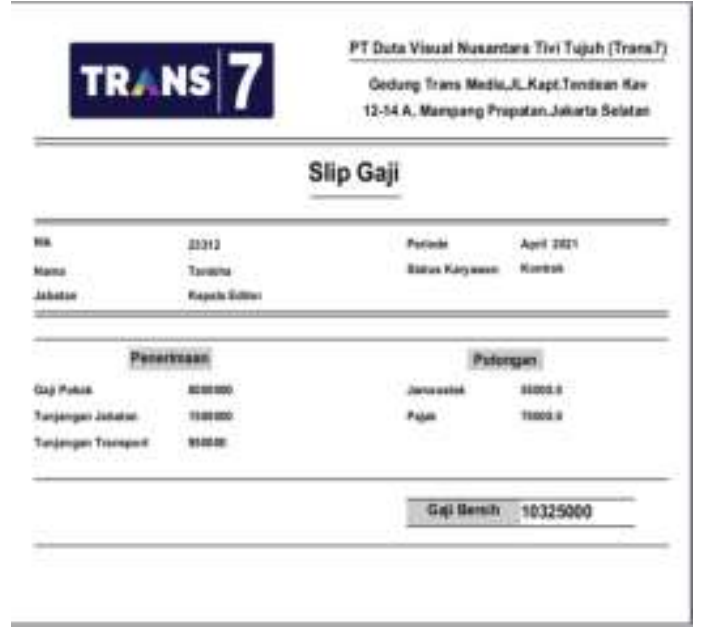

Gambar 13. Tampilan Laporan Data Penggajian

Tampilan slip gaji merupakan tandabukti pembayaran gaji kepada karyawan.

\section{SIMPULAN DAN SARAN}

Dengan dibuatnya aplikasi perancangan sistem informasi penggajian karyawan pada PT Duta Visual Nusantara Tivi Tujuh (TRANS7), penulis menarik beberapa kesimpulan diantaranya adalah : Dengan adanya aplikasi perancangan sistem informasi penggajian karyawan ini maka data penggajian dan data laporan penggajian karyawan dapat tersimpan dengan baik dan aman karena data sudah tersimpan kedalam database.

Dengan adanya aplikasi perancangan sistem informasi penggajian karyawan ini mampu menangani masalah yang terjadi seperti pembuatan laporan yang masih menggunakan MS Office Exel menjadi lebih efisien dan mudah. Tujuan pembuatan program aplikasi perancangan sistem informasi penggajian karyawan ialah antara pihak perusahaan dengan karyawan akan dapat di organisir dengan baik pada saat penerimaan slip gaji.

Peneliti berharap bahwa pengembangan aplikasi penggajian karyawan dapat diperbaiki dan ditingkatkan lagi sehingga menjadi lebih menarik dan interaktif bagi pengguna dari segi desain dan tata letak

\section{UCAPAN TERIMAKASIH}

Penulis mengucapkan Terima Kasih kepada Trans7 serta Trans Media dan berbagai pihak yang sangat membantu dalam jalannya penelitian.
DAFTAR PUSTAKA

Zaki Baridwan dalam Brestina Gultom (2014:96). Sistem Informasi Penggajian. 96.

Hutahaean(2015:13) Konsep Sistem Informasi (Published).

Akhmad Syukron., \& Noor Hasan. (2015:29).. Perancangan Sistem Informasi Rawat Jalan Berbasis Web Pada Puskesmas Winong. Bianglala Informatika Vol 3 No. 1 Maret 2015., 3, 29.

A. S Rosa dan M. Salahuddin. (2016:2). Rekayasa Perangkat Lunak Terstruktur dan Berorientas Objek. Informatika Bandung.

Mulyadi (2016:309). Sistem Akuntansi. Jakarta

A. S Rosa dan M. Salahuddin.(2016:4). Rekayasa Perangkat Lunak Terstruktur dan Berorientas Objek. Informatika Bandung.

Sibero (2013:97). Web Programming Power Pack. Yogyakarta:MediaKom.

Sutanta (2011:91).Basis Data Dalam Tinjauan Konseptual. Yogyakarta.

Sukamto dan M. Salahuddin.(2015:70). Modul Rekayasa Perangkat Lunak Terstruktur dan Berorientas Objek. Bandung.

Sugiyono (2018:2).metodelogi penelitian. Bandung. 